\title{
The association between adolescent entry into the trucking industry and risk of HIV among long-distance truck drivers in India
}

This article was published in the following Dove Press journal:

HIVIAIDS - Research and Palliative Care

3I August 2012

Number of times this article has been viewed

\author{
Ram Manohar Mishra' \\ Madhulika Dube ${ }^{2}$ \\ Niranjan Saggurti' \\ Arvind Pandey ${ }^{3}$ \\ Bidhubhusan Mahapatra' \\ Sowmya Ramesh' \\ 'Population Council, New Delhi, \\ ${ }^{2}$ Department of Statistics, Maharshi \\ Dayanand University, Rohtak, \\ Haryana, ${ }^{3}$ National Institute of \\ Medical Statistics, Indian Council of \\ Medical Research, New Delhi, India
}

Correspondence: Ram Manohar Mishra HIV and AIDS Program, Population Council, Zone 5A, Ground Floor, India Habitat Centre, Lodi Road, New Delhi I 10003 , India

Tel +9| I | 2465 |3 |4

Fax +9| I| 24645060

Email rammanohar7@yahoo.co.in

\begin{abstract}
This study examines the relationship between entry into the trucking industry during adolescence and both sexually transmitted infections (STIs) and infection by the human immunodeficiency virus (HIV) among long-distance truck drivers in India. Data were sourced from a cross-sectional survey (sample size: 2066) undertaken in 2007 among long-distance truck drivers. The survey spread across major transshipment locations covering the bulk of India's transport volume along four routes. Participants were interviewed about sexual behaviors and were tested for HIV and STIs. The present authors constructed two synthetic cohorts based on the participants' duration of employment in the trucking industry: (1) low (duration $\leq 6$ years) and (2) high experience (duration $\geq 7$ years). Based on age at entry into the trucking industry, participants were termed as either adolescent (age at entry $<18$ complete years) or adult entrants (age at entry $\geq 18$ complete years). In the low-experience cohort, the adolescent entrants were more likely than the adult entrants to have sex with paid female partners $(42.6 \%$ versus $27.2 \%$, respectively; adjusted odds ratio [OR]: 1.9; 95\% confidence interval [CI]: 1.3-2.9) and to practice inconsistent condom use with such partners $(69.1 \%$ versus $26.8 \%$, respectively; adjusted OR: 5.3; 95\% CI: 2.4-11.6). However, no significant differences were found in STI and HIV prevalence between the adolescent and the adult entrants in this cohort. In the high-experience cohort, the adolescent entrants were about two times more likely than the adult entrants to practice inconsistent condom use with paid female partners (38.5\% versus $26.7 \%$, respectively; adjusted OR: $1.7 ; 95 \% \mathrm{CI}: 1.1-2.8$ ) and to test positive for HIV (7.4\% versus $4.0 \%$, respectively; adjusted OR: 1.9 ; 95\% CI: $1.2-3.1)$ and syphilis (5.7\% versus $3.5 \%$, respectively; adjusted OR: $1.8 ; 95 \%$ CI: 1.1-3.1). These results suggest the need for focused behavioral change programs in HIV prevention interventions for adolescent truckers in India and elsewhere.
\end{abstract}

Keywords: sexually transmitted infections, condom use, risky sexual behavior, truckers

\section{Introduction}

It is well documented that long-distance truck drivers and their helpers (collectively referred to as truckers) play an important role in the spread of sexually transmitted infections (STIs) and the human immunodeficiency virus (HIV) in many parts of the world, including India. ${ }^{1-10}$ Recent evidence suggests that about one-quarter of the long-distance truck drivers in India have sex with female sex workers (FSWs), ${ }^{7,11,12}$ constituting about $15 \%-20 \%$ of clients of FSWs, ${ }^{8}$ and a substantial proportion have sexual relationships with casual unpaid female partners. ${ }^{711}$ Studies conducted during 2007-2010 have shown that the rate of consistent condom use among truckers in India was low, at 58\%-74\% with FSWs and 18\%-37\% with casual unpaid female sex partners. ${ }^{7,11,12}$ Several studies across the country have confirmed high HIV (2\%-16\%) and STI (3\%-13\%) prevalence among long-distance truckers. ${ }^{9}, 12$ 
Truckers constitute a heterogeneous population. Studies conducted in India indicate that current age, marital status, literacy, duration of employment in the trucking industry, duration of time spent away from home, alcohol consumption, and the specific routes on which the truckers usually travel correlate with different levels of risky sexual behavior and the corresponding prevalence of STIs and HIV among truckers., ${ }^{911,12}$ However, an issue that has received less focus so far is the possible effect of the age at which truckers enter the trucking industry on their sexual behavior and STI/HIV status.

Although little is known about the sexual behavior of adolescent truckers in India, it has been observed that most of the long-distance truck drivers start working as helpers, with a substantial number entering the industry in their adolescence, ${ }^{13}$ and some adolescent helpers in the past have reported visiting FSWs. ${ }^{14}$ Considering that adolescents have a tendency to take greater risks than adults ${ }^{15-17}$ and that behaviors established during adolescence may continue into later adolescence and early adulthood, ${ }^{15,18,19}$ it may be argued that truck drivers who enter the trucking industry in adolescence may have higher vulnerability toward STIs and HIV infection than those who enter the industry as adults. Therefore, in this paper, the authors examine the effect of adolescent entry into the trucking industry on sexual behavior and STI/HIV status among long-distance truck drivers in India. Since longer duration of employment in the trucking industry correlates with a higher risk among truck drivers for contracting STIs and HIV, ${ }^{9,11}$ this study also examines the effects of adolescent entry into the trucking industry on sexual behavior and STI/HIV status by duration of employment in the trucking industry.

\section{Methods}

\section{Study settings and sampling}

The authors used data from a cross-sectional behavioral and biological survey conducted in 2007 among long-distance truck drivers in India. Long-distance truck drivers were defined as truck drivers traveling to destinations over $800 \mathrm{~km}$ from their point of origin. The survey was undertaken at seven transshipment locations covering the bulk of India's transport volume along four routes: North-East, North-South, North-West, and South-East. Transshipment locations are places where transporters and brokers operate by linking truckers with individuals wanting to have goods transported; route categories are road corridors traveled by long-distance truck drivers.

A two-stage time-location cluster sampling approach was used to select respondents for the survey, covering
2066 long-distance truck drivers, a participation rate of 97\%. Participation followed written informed consent, and all data were recorded in an anonymously linked manner using numerically coded cards. Behavioral data, including information about demographics, work, sexual partners, and condom use, were collected through face-to-face interviews, using a pretested, precoded questionnaire translated into local languages. Blood and urine samples were collected from all participating truckers. A blood sample $(5 \mathrm{~mL})$, obtained by antecubital venipuncture, was collected in a vacutainer, clotted for separation of serum, and stored at $2^{\circ} \mathrm{C}-8^{\circ} \mathrm{C}$. A $30 \mathrm{~mL}$ urine sample was collected, from which $2 \mathrm{~mL}$ was stored in a urine specimen transport tube as per the protocol of the Aptima Combo $2^{\circledR}$ Assay (Gen-Probe Incorporated, San Diego, CA). Sera were tested for both HIV-1 and HIV-2 using the Microlisa HIV ${ }^{\circledR}$ kit (J Mitra \& Co, Pvt Ltd, New Delhi, India) and the Genedia ${ }^{\circledR}$ HIV $1 / 2$ ELISA 3.0 Kit (Green Cross Medical Science Corp, Chungbuk, Korea). Serologic tests for syphilis were performed using the Rapid Plasma Reagin Test Kit (Span Diagnostics Limited, Surat, India) and reactive serology was confirmed by Treponema pallidum hemagglutination assay (TPHA) (Syphagen TPHA Kit; Biokit, SA, Lliça d'Amunt, Spain). All cases with reactive rapid plasma reagin serology and TPHA positivity were considered positive for syphilis. To diagnose Neisseria gonorrhoeae and Chlamydia trachomatis infections, urine samples were tested using the TranscriptionMediated Amplification Assay and the Dual Kinetic Assay (Gen-Probe Incorporated).

\section{Ethical considerations}

All relevant institutional review boards (Health Ministry Screening Committee, Government of India; Scientific Advisory Committee, National AIDS Research Institute; Protection of Human Subjects Committee, Family Health International; and Scientific Advisory Committee and Ethical Committee, National Institute of Medical Statistics) approved the study. As stated, participation followed written informed consent, and all data were recorded in an anonymously linked manner using numerically coded cards. Participants were given information on safe sex practices and HIV prevention and care facilities in the area. Numerically coded cards were provided to the participants for receiving test results and free treatment for syphilis at clinics being run under the Kavach HIV prevention program for truckers at major transshipment locations around India. More information about the survey methodology and salient findings can be found elsewhere. ${ }^{10,20,21}$ 


\section{Measures}

\section{Sociodemographic and work-related characteristics}

The sociodemographic and work-related characteristics of respondents included age (in completed years), literacy (defined as ability to read and write [yes/no]), marital status (currently married/not currently married), ownership of truck by respondent (yes/no), and route category (North-East, North-South, North-West, South-East).

\section{Adolescent and adult entrants}

The key independent variable in this study was the age at which respondents entered the trucking industry. Drivers who entered the industry before 18 complete years of age were termed adolescent entrants, while those who entered the industry at 18 complete years of age or older were termed adult entrants. The cutoff age of 18 years was chosen because it is the legal age of adulthood in India, when people are expected to be mature enough to be given important rights such as the right to vote ${ }^{22}$ or the right to consume tobacco products. ${ }^{23,24}$

\section{Duration of employment in the trucking industry}

Two synthetic cohorts (termed low-experience and highexperience cohorts) were constructed based on the respondents' duration of employment in the trucking industry. The low-experience cohort comprised respondents who had worked as truckers for 6 years or less, while the highexperience cohort comprised those who had worked as truckers for 7 years or more. The cutoff point was selected to be 6 years because the difference in the average age at entry into the trucking industry for adolescent and adult entrants, as shown in the preliminary analysis of the data (see "Statistical analyses" section), was about 6 years.

\section{Sexual behavior}

Multiple indicators were used to measure the sexual behavior of respondents. These included age at first sexual intercourse; sexual partnerships with paid female partners, nonpaid female partners, and male or transgender partners; and inconsistent condom use with these partners. "Paid female partner" was defined as a woman to whom the respondent paid cash in exchange for sex. "Nonpaid female partner" was defined as a woman to whom the respondent was not married and to whom the respondent did not pay cash in exchange for sex. "Inconsistent condom use" was defined as failure to use a condom in every sexual encounter with a particular type of sexual partner for a minimum of the past 12 months. To assess inconsistent condom use, participants were asked, for each type of sexual partner, whether they used a condom in each sexual act and the time elapsed since they had been using condoms in every sexual act with the particular type of sexual partner. Using these questions, dummy variables for inconsistent condom use with the different types of sexual partners were computed.

\section{Prevalence of STIs and HIV infection}

A respondent was considered to have an STI if at least one of the following three STIs, for which prevalence was given, was found to be present: syphilis, $N$. gonorrhoeae, and C. trachomatis. A respondent was termed HIV positive if he tested positive for HIV-1, HIV-2, or both.

\section{Statistical analyses}

Appropriate sampling weights were used to account for differential probabilities of selection and for differential nonresponse rates across survey locations. Use of sampling weights provided unbiased estimates of the proportions, averages, and regression coefficients. Details regarding calculation of sampling weights are described elsewhere. ${ }^{20}$ Cross-tabulations were used to examine the differences in background characteristics, sexual behavior, and STI and HIV prevalence between the adolescent and the adult entrants and between the low-experience and the high-experience cohorts. The chi-square test and the unpaired $t$-test were applied to test the significance of the differences in sociodemographic characteristics. To assess the effects of age at entry into and duration of employment in the trucking industry on sexual behavior and STI/HIV prevalence among truck drivers, separate multivariate logistic regression models were estimated with the following binary (yes/no) outcome variables: (1) whether had first sexual intercourse before the age of 18 years; (2) whether had sex with paid female partners in the past 12 months; (3) whether practiced inconsistent condom use with paid female partners in the past 12 months; (4) whether had sex with nonpaid female partners in the past 12 months; (5) whether practiced inconsistent condom use with nonpaid female partners in the past 12 months; (6) whether had sex with male or transgender partners in the past 12 months; (7) whether tested positive for HIV; (8) whether tested positive for syphilis; and (9) whether tested positive for any STI. All sociodemographic and work-related characteristics except for current age were controlled in the multivariate analyses to estimate adjusted odds ratios (ORs) and their 95\% confidence intervals (CIs). The current age of the respondents was not included in the model so as to avoid problems of collinearity, as current age was determined by variables measuring 
age at entry into and duration of employment in the trucking industry. Analyses were repeated and stratified by duration of employment in the trucking industry, because of its strong association with STI and HIV status among truck drivers. The statistical software Stata (v 11.1; StataCorp LP, College Station, TX) was used for analyses.

\section{Results}

Of the 2066 respondents covered in the survey, 555 (26.9\%) were adolescent entrants and 1511 (73.1\%) were adult entrants. A total of 705 (34.1\%) participants belonged to the low-experience cohort, and 1361 (65.9\%) belonged to the high-experience cohort. The low-experience and high-experience cohorts had 113 (16.0\%) and 442 (32.5\%) adolescent entrants, respectively (Table 1). Compared with adult entrants, a significantly lower proportion of adolescent entrants were currently married $(75.7 \%$ versus $68.5 \%$, respectively; $P=0.01)$ and owned a truck $(16.9 \%$ versus $7.1 \%$, respectively; $P=0.01)$. Compared with participants from the low-experience cohort, a significantly higher proportion of participants from the high-experience cohort were currently married (56.3\% versus $82.9 \%$, respectively; $P<0.01)$. Compared with participants from the highexperience cohort, a higher proportion of participants from the low-experience cohort were able to both read and write $(84.7 \%$ versus $90.1 \%$, respectively; $P=0.01)$ and owned a truck $(12.5 \%$ versus $17.6 \%$, respectively; $P=0.02$ ).

Table 2 shows that adolescent entrants were about four times more likely than adult entrants to have experienced their first sexual intercourse before the age of 18 years (54.5\% versus $25.5 \%$, respectively; adjusted OR: 3.6; 95\% CI: 2.9-4.4), about two times more likely than adult entrants to have practiced inconsistent condom use with paid female partners in the past 12 months (46.4\% versus 26.8\%, respectively; adjusted OR: 2.2 ; 95\% CI: 1.5-3.2), about three times more likely than adult entrants to have had sex with male or transgender partners in the past 12 months (5.3\% versus $1.9 \%$, respectively; adjusted OR: 2.7; 95\% CI: 1.6-4.7), and about two times more likely than adult entrants to test positive for HIV (6.0\% versus 2.6\%, respectively; adjusted OR: 2.4; 95\% CI: 1.5-3.9) and syphilis $(4.6 \%$ versus $2.7 \%$, respectively; adjusted OR: $1.8 ; 95 \%$ CI: 1.1-3.0). Differences in sexual behaviors of participants between the low-experience and the highexperience cohorts in the past 12 months could not reach statistical significance. However, participants belonging to the high-experience cohort were more likely than those from the low-experience cohort to test positive for HIV (5.1\% versus $0.4 \%$, respectively; adjusted OR: $17.3 ; 95 \%$ CI: $5.1-58.4)$ and syphilis (4.2\% versus $1.2 \%$, respectively; adjusted OR: 3.5 ; 95\% CI: $1.6-7.4)$.

Table I Sociodemographic and work-related characteristics of long-distance truck drivers by age at entry into and duration of employment in the trucking industry (India, 2007)

\begin{tabular}{|c|c|c|c|c|c|c|}
\hline \multirow{2}{*}{$\begin{array}{l}\text { Sociodemographic and } \\
\text { work-related characteristics }\end{array}$} & \multicolumn{3}{|c|}{ Age at entry into trucking industry } & \multicolumn{3}{|c|}{ Duration of employment in trucking industry } \\
\hline & $\begin{array}{l}\text { Adolescent entrants }^{a} \\
(n=555)\end{array}$ & $\begin{array}{l}\text { Adult entrants }^{b} \\
(n=I 5 I I)\end{array}$ & $P$-value & $\begin{array}{l}\text { Low experience } \\
(n=705)\end{array}$ & $\begin{array}{l}\text { High experience }^{d} \\
(n=136 \mathrm{I})\end{array}$ & $P$-value \\
\hline Mean current age [years (SD)] & $29.0(7.7)$ & $31.8(7.8)$ & $<0.0 \mathrm{I}$ & $25.4(4.9)$ & $33.9(7.5)$ & $<0.01$ \\
\hline Literacye $(\%)$ & 83.7 & 87.6 & 0.03 & 90.1 & 84.7 & 0.01 \\
\hline Currently married (\%) & 68.5 & 75.7 & 0.01 & 56.3 & 82.9 & $<0.01$ \\
\hline $\begin{array}{l}\text { Mean age at entry into trucking } \\
\text { industry [years (SD)] }\end{array}$ & $15.8(1.4)$ & $21.6(4.0)$ & $<0.01$ & $21.2(5.0)$ & $19.5(3.8)$ & $<0.01$ \\
\hline $\begin{array}{l}\text { Mean duration of employment } \\
\text { in trucking industry [years (SD)] }\end{array}$ & $12.8(7.2)$ & $9.9(6.6)$ & $<0.01$ & $4.2(1.5)$ & $14.2(6.1)$ & $<0.01$ \\
\hline Ownership of truck (\%) & 7.1 & 16.9 & 0.01 & 17.6 & 12.5 & 0.02 \\
\hline \multicolumn{7}{|l|}{ Route category $(\%)$} \\
\hline North-East & 30.9 & 24.3 & 0.03 & 20.6 & 28.9 & $<0.01$ \\
\hline North-South & 25.2 & 25.9 & & 24.7 & 26.3 & \\
\hline North-West & 37.2 & 45.1 & & 52.8 & 37.9 & \\
\hline South-East & 6.6 & 4.7 & & 1.95 & 6.85 & \\
\hline \multicolumn{7}{|l|}{ Age at entry into trucking industry } \\
\hline Adolescent entrants & - & - & & 16.0 & 32.5 & $<0.01$ \\
\hline Adult entrants & - & - & & 84.0 & 67.5 & \\
\hline
\end{tabular}

Notes: "Adolescent entrants" defined as age at entry into trucking industry $<18$ complete years; " "adult entrants" defined as age at entry into trucking industry $\geq 18$ complete years; "low experience" defined as duration of employment in trucking industry $\leq 6$ years; "“high experience" defined as duration of employment in trucking industry $\geq 7$ years; e"literacy" refers to the ability to both read and write; "route category" refers to the road corridors on which the respondent usually travels; significance of difference in percentages across categories was tested using the chi-square test; significance of difference in average values was tested using the unpaired $t$-test.

Abbreviation: SD, standard deviation. 
Table 2 Sexual behavior and prevalence of sexually transmitted infections (STIs) and human immunodeficiency virus (HIV) infection among long-distance truck drivers by age at entry into and duration of employment in the trucking industry (India, 2007)

\begin{tabular}{|c|c|c|c|c|c|c|}
\hline \multirow{2}{*}{$\begin{array}{l}\text { Sexual behavior and } \\
\text { STI/HIV prevalence }\end{array}$} & \multicolumn{3}{|c|}{ Age at entry into trucking industry } & \multicolumn{3}{|c|}{ Duration of employment in trucking industry } \\
\hline & $\begin{array}{l}\text { Adolescent entrants }^{\mathrm{a}} \\
{[\%(\mathrm{~N})]}\end{array}$ & $\begin{array}{l}\text { Adult entrants }{ }^{\mathrm{b}} \\
{[\%(\mathrm{~N})]}\end{array}$ & $\begin{array}{l}\text { Adjusted OR }{ }^{c} \\
(95 \% \mathrm{Cl})\end{array}$ & $\begin{array}{l}\text { Low experience }^{d} \\
{[\%(N)]}\end{array}$ & $\begin{array}{l}\text { High experience }^{\mathrm{e}} \\
{[\%(\mathrm{~N})]}\end{array}$ & $\begin{array}{l}\text { Adjusted OR } \\
(95 \% \mathrm{Cl})\end{array}$ \\
\hline $\begin{array}{l}\text { Age at first sexual } \\
\text { intercourse }<18 \text { years }\end{array}$ & $54.5(555)$ & $25.5(I 5 I I)$ & $3.6(2.9-4.4)$ & $27.2(705)$ & $36.5(|36|)$ & $1.5(1.2-1.9)$ \\
\hline \multicolumn{7}{|l|}{ (past 12 months) } \\
\hline Had sex with & $33.8(555)$ & $27.1(1511)$ & $1.3(1.1-1.6)$ & $29.7(705)$ & $28.4(|36|)$ & $1.2(1.0-1.5)$ \\
\hline $\begin{array}{l}\text { Inconsistent condom } \\
\text { use with }\end{array}$ & $46.4(188)$ & $26.8(408)$ & $2.2(1.5-3.2)$ & $36.5(209)$ & $30.9(387)$ & $0.7(0.5-1.1)$ \\
\hline \multicolumn{7}{|l|}{$\begin{array}{l}\text { Nonpaid female partners } \\
\text { (past } 12 \text { months) }\end{array}$} \\
\hline Had sex with & $21.3(555)$ & $20.0(I 5 I I)$ & $1.0(0.8-1.3)$ & $27.9(705)$ & $16.5(|36|)$ & $0.8(0.6-1.1)$ \\
\hline $\begin{array}{l}\text { Inconsistent condom } \\
\text { use with }\end{array}$ & $81.8(118)$ & $79.7(302)$ & $0.7(0.4-1.2)$ & $80.0(195)$ & $80.5(225)$ & $1.0(0.6-2.1)$ \\
\hline \multicolumn{7}{|l|}{ Male or transgender } \\
\hline Had sex with & $5.3(555)$ & $1.9(1511)$ & $2.7(1.6-4.7)$ & $4.4(705)$ & $2.0(136 \mid)$ & $0.9(0.5-1.5)$ \\
\hline $\begin{array}{l}\text { Inconsistent condom } \\
\text { use with }\end{array}$ & $87.2(29)$ & $65.6(29)$ & NE & $75.6(31)$ & $77.6(27)$ & NE \\
\hline \multicolumn{7}{|l|}{ STI/HIV prevalence } \\
\hline HIV & $6.0(555)$ & $2.6(1511)$ & $2.4(1.5-3.9)$ & $0.4(705)$ & $5.1(1361)$ & I7.3 (5.|-58.4) \\
\hline Syphilis & $4.6(555)$ & $2.7(1511)$ & $1.8(1.1-3.0)$ & I.2(705) & $4.2(1361)$ & $3.5(1.6-7.4)$ \\
\hline Neisseria gonorrhoeae & $0.7(555)$ & $0.1(1511)$ & $\mathrm{NE}$ & $0.0(705)$ & $0.4(1361)$ & NE \\
\hline Chlamydia trachomatis & $0.9(555)$ & $0.1(15 I I)$ & NE & $0.1(705)$ & $0.4(|36|)$ & NE \\
\hline Any STIg & 6.1 (555) & $2.8(1511)$ & $2.3(1.4-3.7)$ & I.3 (705) & $4.9(1361)$ & $3.7(1.8-7.5)$ \\
\hline
\end{tabular}

Notes: "Adolescent entrants" defined as age at entry into the trucking industry $<18$ complete years; "adult entrants" defined as age at entry into the trucking industry $\geq 18$ complete years; 'ORs were adjusted for literacy (yes/no), marital status (currently married/not currently married), ownership of truck by respondent (yes/no), and route categories (North-East, North-South, North-West, South-East) by using multivariate logistic regression analyses; adult entrants were considered as reference category to examine the effects of age at entry into the trucking industry on outcomes. Low experience cohort was considered as reference category to examine the effect of duration of employment in the trucking industry on outcomes. "low experience" defined as duration of employment in the trucking industry $\leq 6$ years; " "high experience" defined as duration of employment in the trucking industry $\geq 7$ years; multivariate logistic regression models were not estimated because of small cell frequencies; " "any STI" defined as presence of at least one of the three STIs syphilis, N. gonorrhoeae, and C. trachomatis.

Abbreviations: $\mathrm{Cl}$, confidence interval; NE, not estimable; OR, odds ratio.

Table 3 shows results from the duration-stratified analyses. Adolescent entrants were significantly more likely than adult entrants to have experienced their first sexual intercourse before the age of 18 years, both in the low-experience (46.3\% versus $23.6 \%$, respectively; adjusted OR: 2.8 ; $95 \%$ CI: $1.8-4.3)$ and the high-experience cohort (56.6\% versus $26.8 \%$, respectively; adjusted OR: $3.8 ; 95 \%$ CI: $3.0-4.9)$. In the low-experience cohort, the adolescent entrants were about twice as likely as the adult entrants to have had sex with paid female partners in the past 12 months (42.6\% versus $27.2 \%$, respectively; adjusted OR: 1.9; 95\% CI: 1.3-2.9), about five times more likely than the adult entrants to practice inconsistent condom use in such relationships (69.1\% versus $26.8 \%$, respectively; adjusted OR: 5.3; 95\% CI: 2.4-11.6), and about four times more likely than the adult entrants to have sex with male or transgender partners (17.7\% versus $1.9 \%$, respectively; adjusted OR: 3.8; 95\% CI: 1.7-11.2). However, no significant differences were found in STI and HIV prevalence between the adolescent and the adult entrants in this cohort. In the high-experience cohort, the adolescent entrants were about two times more likely than the adult entrants to practice inconsistent condom use with paid female partners $(38.5 \%$ versus $26.7 \%$, respectively; adjusted OR: $1.7 ; 95 \%$ CI: $1.1-2.8$ ) and to test positive for HIV (7.4\% versus $4.0 \%$, respectively; adjusted OR: $1.9 ; 95 \%$ CI: $1.2-3.1)$ and syphilis (5.7\% versus $3.5 \%$, respectively; adjusted OR: $1.8 ; 95 \%$ CI: $1.1-3.1$ ).

\section{Discussion}

This study shows that long-distance truck drivers in India who enter the trucking industry during their adolescence are at significantly higher risk of contracting STIs and HIV than those who enter the industry as adults. The duration of employment in the trucking industry also exhibits significant association with higher STI and HIV prevalence, especially among the adolescent entrants. Adolescent entrants were more likely to experience sexual debut at an early age, exhibit high-risk sexual behavior, and exhibit higher STI and HIV prevalence than adult entrants. The differential in sexual behavior between the ado- 
Table 3 Effect of age at entry into the trucking industry on sexual behavior and prevalence of sexually transmitted infections (STIs) and human immunodeficiency virus (HIV) infection among long-distance truck drivers stratified by duration of employment in the trucking industry (India, 2007)

\begin{tabular}{|c|c|c|c|c|c|c|}
\hline \multirow{2}{*}{$\begin{array}{l}\text { Sexual behavior and } \\
\text { STI/HIV prevalence }\end{array}$} & \multicolumn{3}{|l|}{ Low experience } & \multicolumn{3}{|l|}{ High experience } \\
\hline & $\begin{array}{l}\text { Adolescent entrants }^{a} \\
{[\%(N)]}\end{array}$ & $\begin{array}{l}\text { Adult entrants } \\
{[\%(\mathrm{~N})]}\end{array}$ & $\begin{array}{l}\text { Adjusted OR } \\
(95 \% \mathrm{CI})\end{array}$ & $\begin{array}{l}\text { Adolescent entrants }^{d} \\
{[\%(N)]}\end{array}$ & $\begin{array}{l}\text { Adult entrants } \\
{[\%(N)]}\end{array}$ & $\begin{array}{l}\text { Adjusted OR } \\
(95 \% \mathrm{CI})\end{array}$ \\
\hline \multicolumn{6}{|l|}{$\begin{array}{l}\text { Paid female partners } \\
\text { (past } 12 \text { months) }\end{array}$} & $3.8(3.0-4.9)$ \\
\hline Had sex with & $42.6(113)$ & $27.2(592)$ & $1.9(1.3-2.9)$ & $31.5(442)$ & $26.9(919)$ & I.I (0.8-I.4) \\
\hline $\begin{array}{l}\text { Inconsistent condom } \\
\text { use with }\end{array}$ & $69.1(48)$ & $26.8(161)$ & $5.3(2.4-11.6)$ & 38.5 (I39) & $26.7(247)$ & $1.7(1.1-2.8)$ \\
\hline \multicolumn{7}{|l|}{$\begin{array}{l}\text { Nonpaid female partners } \\
\text { (past } 12 \text { months) }\end{array}$} \\
\hline Had sex with & $30.8(113)$ & $27.3(592)$ & $0.7(0.3-1.5)$ & $18.9(442)$ & $15.3(9 \mid 9)$ & $1.0(0.6-1.7)$ \\
\hline $\begin{array}{l}\text { Inconsistent condom } \\
\text { use with }\end{array}$ & $87.6(35)$ & $78.4(162)$ & $1.3(0.2-8.1)$ & $79.4(84)$ & $81.2(14 I)$ & I.I (0.5-3.9) \\
\hline \multicolumn{7}{|c|}{$\begin{array}{l}\text { Male or transgender } \\
\text { partners (past } 12 \text { months) }\end{array}$} \\
\hline Had sex with & $17.7(1 \mid 3)$ & $1.9(592)$ & $3.8(|.7-| \mid .2)$ & $2.1(442)$ & $2.0(919)$ & I.I $(0.5-3.1)$ \\
\hline $\begin{array}{l}\text { Inconsistent condom } \\
\text { use with }\end{array}$ & $94.2(20)$ & $4 I .6(I I)$ & NE & $71.8(9)$ & $80.5(18)$ & NE \\
\hline \multicolumn{7}{|l|}{ STI/HIV prevalence } \\
\hline HIV & $0.7^{f}$ & $0.3^{f}$ & NE & $7.4^{f}$ & $4.0^{f}$ & $1.9(1.2-3.1)$ \\
\hline Syphilis & $0.4^{f}$ & $1.3^{f}$ & NE & $5.7^{f}$ & $3.5^{f}$ & $1.8(1.1-3.1)$ \\
\hline Neisseria gonorrhoeae & $0.0^{f}$ & $0.0^{f}$ & NE & $0.9^{f}$ & $0.2^{f}$ & NE \\
\hline Chlamydia trachomatis & $0.7^{f}$ & $0.0^{f}$ & NE & $0.9^{f}$ & $0 . I^{f}$ & NE \\
\hline Any STIg & I.I (II3) & I.3 (592) & $1.3(0.3-19.7)$ & $7.4(442)$ & $3.8(919)$ & $2.1(1.3-3.6)$ \\
\hline
\end{tabular}

Notes: "adolescent entrants" defined as age at entry into the trucking industry < 18 complete years; "adult entrants" defined as age at entry into the trucking industry $\geq 18$ complete years; 'ORs were adjusted for literacy (yes/no), marital status (currently married/not currently married), ownership of truck by respondent (yes/no), and route categories (North-East, North-South, North-West, South-East) by using multivariate logistic regression analyses; adults entrants were considered as reference category; ${ }^{\text {d“low }}$ experience" defined as duration of employment in the trucking industry $\leq 6$ years; " "high experience" defined as duration of employment in the trucking industry $\geq 7$ years; multivariate logistic regression models were not estimated because of small cell frequencies; 'total in group not shown; "any STI" defined as presence of at least one of the three STIs syphilis, N. gonorrhoeae, and C. trachomatis.

Abbreviations: $\mathrm{Cl}$, confidence interval; $\mathrm{NE}$, not estimable; $\mathrm{OR}$, odds ratio.

lescent and the adult entrants was particularly substantial in the low-experience cohort, whereas the differential in STI and HIV prevalence between the adolescent and the adult entrants could reach statistical significance in the high-experience cohort.

These findings are consistent with results from research in various other settings that determined early initiation of sexual intercourse was linked with HIV high-risk behavior ${ }^{25-29}$ and was associated with longer periods of risk taking in later adolescence and early adulthood. ${ }^{15-19}$ This evidence suggests that sexual debut at an early age may be one of the critical factors behind the differential in high-risk sexual behavior between adolescent and adult entrants in the low-experience cohort. The higher vulnerability of adolescent entrants compared with that of adult entrants may also be explained, at least partly, by the following two factors: first, adolescent boys who are believed to be "risk takers" - owing to a combination of physiological sexual urge, peer influences, and a need for experimentation ${ }^{16,17}$ - are more likely to engage in riskier behaviors, including commercial sex and sexual relationships with male or transgender partners, if exposed to the environmental factors associated with the trucking industry, such as high mobility, easy access to FSWs, and interaction with men who are often away from their families (eg, senior drivers, other helpers, males working at roadside eating establishments, transgender people, and so forth); second, some of the senior drivers force adolescent helpers into "survival sex." The ability of helpers to resist and negotiate with the senior drivers is often limited, because in most cases they are appointed on contract by the drivers themselves. ${ }^{30}$ Although this study did not collect specific information about coerced sexual activities between drivers and helpers, this could be an important area for future research and intervention.

The low STI and HIV prevalence observed in the low-experience cohort could be explained, at least to some extent, by several factors such as the overall declining trend in STI and HIV prevalence in India among high-risk groups 
(including truckers, FSWs, and men who have sex with male or transgender partners), ${ }^{11,31,32}$ implementation of high-intensity HIV prevention programs among high-risk groups during the past decade, ${ }^{32,33}$ and the low infectivity of HIV through unprotected sexual contact in the absence of STIs. ${ }^{34}$

These findings are important because, to the best of the authors' knowledge, there has not been any study previously that has conducted a detailed examination of the effect of entry into the trucking industry during adolescence on the sexual behavior of long-distance truck drivers in India. A connection between age of entry into the trucking industry and sexual behavior of truckers in India has critical policy implications regarding HIV prevention programs. HIV prevention programs need to cover long-distance truckers during their initial years of working, when the truckers are most likely to initiate the risk-taking behaviors that in the long run result in the higher prevalence of STIs and HIV infection among truckers. Hence, concerted efforts may be required to sensitize and inform adolescent helpers about the risks and consequences of STIs and HIV infection. One possible intervention could be to convince transporters and brokers (the middlemen on whom long-distance truck drivers in India largely depend for their business) to recruit helpers themselves, rather than leaving recruitment primarily to the drivers, and sensitize them to this issue. This may provide some autonomy to helpers in order to avoid sexual relationships forced on them by senior drivers.

Although this study offers important findings, the results must be interpreted cautiously, by considering certain study limitations. The participants in the survey were adults working as long-distance truck drivers. Therefore, the findings are applicable to truckers who either started working as truck drivers or were promoted after working as helpers; the findings are not applicable to individuals who worked as helpers but were never promoted to truck drivers. Nonetheless, considering the high vulnerability of adolescent truckers to STIs and HIV, similar studies are needed among helpers to understand the effects of adolescent entry into the trucking industry on their sexual behavior and STI/HIV status. The behavioral measures used in this study were derived from self-reports, which are vulnerable to recall and social desirability bias. The HIV prevalence among the low-experience cohort was very low, which limited the choices for analysis of HIV data in this cohort.

\section{Conclusion}

In summary, the current study documents that long-distance truck drivers in India who enter the trucking industry during their adolescence are more likely than those who enter the industry as adults to display high-risk behavior and to have higher STI and HIV prevalence. These data highlight the need for HIV prevention programs to start focusing on adolescent truckers as early as possible during their initial years of working in order to maximize the effects of HIV prevention interventions. Losing adolescent truckers from the coverage of HIV prevention programs may be a lost opportunity in preventing truckers from contracting HIV.

\section{Acknowledgments/disclosure}

This paper was written as part of a mentorship program within the Knowledge Network project coordinated by the Population Council, which is a grantee of the Bill and Melinda Gates Foundation through Avahan, the foundation's India AIDS Initiative. The views expressed herein are those of the authors and do not necessarily reflect the official policy or position of the Bill and Melinda Gates Foundation and Avahan.

\section{References}

1. Gibney L, Saquib N, Macaluso M, et al. STD in Bangladesh's trucking industry: prevalence and risk factors. Sex Transm Infect. 2002;78(1): 31-36.

2. Malta M, Bastos FI, Pereira-Koller EM, Cunha MD, Marques C, Strathdee SA. A qualitative assessment of long distance truck drivers' vulnerability to HIV/AIDS in Itajaí, southern Brazil. AIDS Care. 2006;18(5):489-496.

3. Wong WC, Tam SM, Leung PW. Cross-border truck drivers in Hong Kong: their psychological health, sexual dysfunctions and sexual risk behaviors. J Travel Med. 2007;14(1):20-30.

4. Lichtenstein B, Hook EW 3rd, Grimley DM, St Lawrence JS, Bachmann LH. HIV risk among long-haul truckers in the USA. Cult Health Sex. 2008;10(1):43-56.

5. Atilola GO, Akpa OM, Komolafe IO. HIV/AIDS and the long-distance truck drivers in south-west Nigeria: a cross-sectional survey on the knowledge, attitude, risk behaviour and beliefs of truckers. J Infect Public Health. 2010;3(4):166-178.

6. Bal B, Ahmed SI, Mukherjee R, et al. HIV infection among transport workers operating through Siliguri-Guwahati national highway, India. J Int Assoc Physicians AIDS Care (Chic). 2007;6(1):56-60.

7. Sanjeev K, Garg SK, Bajpai SK. A study of knowledge, sexual behaviour and practices regarding HIV/AIDS among long distance truck drivers. Indian J Public Health. 2009;53(4):243-245.

8. National AIDS Control Organization (NACO). National Behavioural Surveillance Survey (BSS): Female Sex Workers (FSWS) and Their Clients. New Delhi, India: NACO; 2006.

9. Manjunath JV, Thappa DM, Jaisankar TJ. Sexually transmitted diseases and sexual lifestyles of long-distance truck drivers: a clinico-epidemiologic study in south India. Int J STD AIDS. 2002;13(9): 612-617.

10. Pandey A, Benara SK, Roy N, et al; for IBBA Study Team. Risk behaviour, sexually transmitted infections and HIV among long-distance truck drivers: a cross-sectional survey along national highways in India. AIDS. 2008;22 Suppl 5:S81-S90.

11. Pandey A, Mishra RM, Sahu D, et al. Heading towards the Safer Highways: an assessment of the Avahan prevention programme among long distance truck drivers in India. BMC Public Health. 2011; 11 Suppl 6:S15.

12. Dude A, Oruganti G, Kumar V, Mayer KH, Yeldandi V, Schneider JA. HIV infection, genital symptoms and sexual risk behavior among Indian truck drivers from a large transportation company in South India. J Glob Infect Dis. 2009;1(1):21-28. 
13. Indian Council of Medical Research, Family Health International (FHI). National Interim Summary Report - India (Oct 2007), Integrated Behavioral and Biological Assessment (IBBA), Round 1 (2005-2007). Pune and New Delhi, India: National AIDS Research Institute and FHI; 2007. Available at http://www.nari-icmr.res.in/IBBA/IBBA-NISR.pdf. Accessed April 29, 2012.

14. Bansal RK. Truck drivers and risk of STDs including HIV. Indian $J$ Community Med. 1995;20(1-4):28-30.

15. Dickson N, Paul C, Herbison P. Adolescents, sexual behaviour and implications for an epidemic of HIV/AIDS among the young. Genitourin Med. 1993;69(2):133-140.

16. Rivers K, Aggleton P. Women and HIV: adolescent sexuality, gender, and the HIV epidemic. BETA. 2001;14(2):35-40.

17. Gandhi KY. Addressing adolescent bisexuality: role of behaviour determinants. Abstract E11601. XIV International AIDS Conference; July 7-12, 2002; Barcelona, Spain. Available from: http://www. iasociety.org/Abstracts/A8720.aspx. Accessed June 10, 2012.

18. O'Donnell BL, O'Donnell CR, Stueve A. Early sexual initiation and subsequent sex-related risks among urban minority youth: the reach for health study. Fam Plann Perspect. 2001;33(6):268-275.

19. Warren CW, Kann L, Small ML, Santelli JS, Collins JL, Kolbe LJ. Age of initiating selected health-risk behaviors among high school students in the United States. J Adolesc Health. 1997;21(4):225-231.

20. Pandey A, Sahu D, Mishra RM, et al. Integrated behavioral and biological assessment: national highways; survey methodology and implementation. Demography India. 2008;37 Suppl:S77-S90.

21. Chandrasekaran P, Dallabetta G, Loo V, et al; for Avahan Evaluation Partners. Evaluation design for large-scale HIV prevention programmes: the case of Avahan, the India AIDS initiative. AIDS. 2008;22 Suppl 5: S1-S15.

22. Government of India. The Constitution (Sixty-First Amendment) Act, 1988. New Delhi, India: National Portal of India. Available from: http:// india.gov.in/govt/documents/amendment/amend61.htm. Accessed May 5, 2012.

23. Kumar S. India steps up anti-tobacco measures. Lancet. 2000; 356(9235): 1089

24. Government of India. The Cigarettes and Other Tobacco Products (Prohibition of Advertisement and Regulation of Trade and Commerce, Production, Supply and Distribution) Act, 2003. New Delhi, India: Ministry of Law and Justice, Legislative Department. Available from: http:// indiacode.nic.in/fullact1.asp?tfnm=200334. Accessed May 5, 2012.
25. Collumbien M, Das B, Bohidar N. Male sexual debut in Orissa, India: context, partners and differentials. Asia Pac Popul J. 2001;16(2):211-224.

26. Coker AL, Richter DL, Valois RF, McKeown RE, Garrison CZ, Vincent ML. Correlates and consequences of early initiation of sexual intercourse. J Sch Health. 1994;64(9):372-377.

27. White R, Cleland J, Caraël M. Links between premarital sexual behaviour and extramarital intercourse: a multi-site analysis. AIDS. 2000;14(15):2323-2331.

28. Pettifor A, O’Brien K, Macphail C, Miller WC, Rees H. Early coital debut and associated HIV risk factors among young women and men in South Africa. Int Perspect Sex Reprod Health. 2009;35(2):82-90.

29. Shaw SY, Emmanuel F, Adrien A, et al. The descriptive epidemiology of male sex workers in Pakistan: a biological and behavioural examination. Sexually Transm Infect. 2011;87(1):73-80.

30. Population Council. Context and Dynamics of Male-to-Male Sexual Behavior of Truckers in India: Findings from a Multi-Site Qualitative Research Study. New Delhi, India: Population Council; 2006.

31. Indian Council of Medical Research, Family Health International (FHI). National Summary Report - India (July 2011), Integrated Behavioural and Biological Assessment (IBBA), Round 2 (2009-2010). New Delhi, India: Indian Council of Medical Research and FHI 360; 2011. Available from: http://aidsdatahub.org/dmdocuments/IBBA_NSR_ R2_2009_2010.pdf. Accessed March 9, 2012.

32. National AIDS Control Organisation. Department of AIDS Control: Ministry of Health and Family Welfare; Annual Report 2009-2010. New Delhi: Ministry of Health and Family Welfare, Government of India. Available from: http://www.nacoonline.org/Quick_Links/ Directory_of_HIV_Data/.Accessed May 2, 2010.

33. Bill and Melinda Gates Foundation (BMGF). Avahan - The India AIDS Initiative: The Business of HIV Prevention at Scale. New Delhi, India: BMGF; 2008.

34. Powers KA, Poole C, Pettifor AE, Cohen MS. Rethinking the heterosexual infectivity of HIV-1: a systematic review and meta-analysis. Lancet Infect Dis. 2008;8(9):553-563.
HIV/AIDS - Research and Palliative Care

\section{Publish your work in this journal}

HIV/AIDS - Research and Palliative Care is an international, peerreviewed open-access journal focusing on advances in research in HIV, its clinical progression and management options including antiviral treatment, palliative care and public healthcare policies to control viral spread. The journal welcomes original research, basic science,

\section{Dovepress}

clinical \& epidemiological studies, reviews \& evaluations, expert opinion \& commentary, case reports \& extended reports. The manuscript management system is completely online and includes a very quick and fair peer-review system. Visit http://www.dovepress.com/ testimonials.php to read real quotes from published authors. 